\title{
Parafoveal activation of sign translation previews among deaf readers during the reading of Chinese sentences
}

\author{
Jinger Pan • Hua Shu • Yuling Wang • Ming Yan
}

Published online: 24 February 2015

(C) Psychonomic Society, Inc. 2015

\begin{abstract}
In the present study, we manipulated the different types of information available in the parafovea during the reading of Chinese sentences and examined whether deaf readers could activate sign translations of Chinese words during reading. The main finding was that, as compared to unrelated previews, the deaf readers had longer fixation durations on the target words when sign-phonologically related preview words were presented; this preview cost effect due to signphonological relatedness was absent for reading-levelmatched hearing individuals. These results indicate that Chinese deaf readers activate sign language translations of parafoveal words during reading. We discuss the implications for notions of parafoveal processing in reading.
\end{abstract}

Keywords Sign language $\cdot$ Parafoveal $\cdot$ Chinese $\cdot$ Deaf readers $\cdot$ Sentence reading

Phonological skill plays an important role in reading acquisition among hearing readers in alphabetic (e.g., Goswami \& Bryant, 1990) and logographic (e.g., Lei et al., 2011) writing systems. Given the absent or limited auditory environment and its consequence of inadequate language exposure, reading acquisition is typically difficult for deaf readers (Kelly \&

J. Pan $(\bowtie) \cdot$ M. Yan $(\bowtie)$

Department of Psychology, University of Potsdam,

Karl-Liebknecht-Str. 24/25, 14476 Potsdam, Germany

e-mail: jinger.pan@uni-potsdam.de

e-mail: mingyan@uni-potsdam.de

H. Shu

State Key Laboratory of Cognitive Neuroscience and Learning,

Beijing Normal University, Beijing, China

Y. Wang

Beijing Experimental School for the Deaf, Beijing, China
Barac-Cikoja, 2007; Mayberry, del Giudice, \& Lieberman, 2011). However, some deaf readers can reach a relatively high reading level, suggesting that they may use a different coding system in lexical processing. Previous studies have demonstrated that deaf readers do not make use of parafoveal phonological information as hearing readers do (Bélanger, Mayberry, \& Rayner, 2013a), and that Chinese deaf readers develop more direct access to parafoveal semantics (Yan, Pan, Bélanger, \& Shu, 2015a). Although these studies have contributed to the understanding of lexical processing for deaf readers, it remains an open question whether or not some types of parafoveal information uniquely contribute to lexical access among deaf readers. Former studies have shown that deaf readers activate sign translations of written words, even if translation is not necessary to perform the task (Morford, Wilkinson, Villwock, Piñar, \& Kroll, 2011). In the present study, we adopted the gaze-contingent boundary paradigm (Rayner, 1975) to examine whether and how deaf readers activate sign translations of parafoveal words.

\section{Preview benefit and preview cost effects in reading}

During reading, lexical information is obtained not only from the currently fixated word, but also from the upcoming word. The gaze-contingent boundary paradigm (Rayner, 1975) has been widely used to study the type(s) of information that can be obtained from parafoveal words. In this paradigm, an invisible boundary is placed between the pretarget and target words. A preview word is located in the position of the target word before it is fixated. During a saccade crossing the boundary, the preview word is immediately replaced by the correct target word. The relation between the preview and the target can be identical, related, or unrelated. Using the unrelated preview as a reference, identical and related previews of the target word normally reduce the fixation duration on the target word when it is subsequently fixated. This facilitation is 
termed the preview benefit (PB), and it has been reported that phonological, orthographic, and semantic information can be obtained in parafoveal vision among hearing readers (Rayner, 2009; Schotter, 2013; Schotter, Angele, \& Rayner, 2012).

Together with the PB, which indicates facilitation in processing the target word due to information overlap between the preview and the target, recent studies have also documented negative PB effects - that is, situations in which earlier or ongoing processing of the previews caused more interference to the processing of the target word, known as the preview cost effect (Kliegl, Hohenstein, Yan, \& McDonald, 2013; Yan, Risse, Zhou, \& Kliegl, 2012a). It is proposed that when a nonidentical parafoveal preview is presented, more parafoveal information leads to a deeper level of lexical processing of the preview, which in turn makes it more likely for the nonoverlapping information between the preview and the target to interfere with the processing of the target word, leading to a preview cost. Previously, the preview cost effect due to related parafoveal preview has typically been shown when a semantically related preview in Chinese is provided. For example, Yan, Risse, et al. (2012a) demonstrated that the size of the semantic PB decreases with increasing fixation durations on pretarget words. Pan, Laubrock, and Yan (2015) reported a semantic PB in silent reading but a semantic preview cost in oral reading. Arguably, this was because the Chinese writing system is well-optimized for fast semantic processing (Hoosain, 1992; Laubrock \& Hohenstein, 2012) and the semantic information in Chinese script is more densely packed than in alphabetic scripts, allowing Chinese readers to efficiently process parafoveal semantics (e.g., Yan, Richter, Shu, \& Kliegl, 2009; Yan, Zhou, Shu, \& Kliegl, 2012b; Yang, Wang, Tong, \& Rayner, 2012). However, in principle, the preview cost should not be limited to semantics; as long as parafoveal processing efficiency is high, there is an opportunity to observe other types of preview costs. Therefore, it will be of great theoretical importance to further explore the preview cost effect and to achieve a better understanding of parafoveal processing. Due to the enhanced parafoveal processing efficiency of deaf readers that we elaborate on below, the present study extends the preview cost effect to sign-based representations for deaf readers.

\section{Parafoveal processing of deaf readers}

Not many studies have addressed the question of the parafoveal processing of deaf readers. Despite their generally low performance in reading, it is known that deaf readers with early-onset deafness process parafoveal (and peripheral) information more efficiently than do hearing readers in low-level visual perception tasks, due to their increased allocation of attention to the stimuli in extrafoveal vision (Bavelier, Dye, \& Hauser, 2006; Dye \& Bavelier, 2010). More relevant to the present study, Bélanger, Slattery, Mayberry, and Rayner (2012b) found that skilled deaf readers have a larger perceptual span (the spatial extent of visual information processing; McConkie \& Rayner, 1975; see Inhoff \& Liu, 1998, and Yan, Zhou, Shu, \& Kliegl, 2015b, for perceptual span in Chinese) than do reading-level-matched hearing readers, suggesting that deaf readers are better at parafoveal information processing.

Recent experiments have further tested the types of information that can be parafoveally obtained by deaf readers: Bélanger, Mayberry, and Rayner (2013a) provided no evidence for parafoveal phonological processing among deaf readers. It is possible that given the lack of auditory input, deaf readers may develop a different coding strategy and/or more direct access to semantics. Indeed, Yan et al. (2015a) found that Chinese deaf readers have earlier and stronger activation of semantics in the parafovea. More critically, the semantic PB was only observed in early fixation measures, and it became numerically negative in late fixation measures, indicating a semantic preview cost. Although these studies contribute to the understanding of lexical processing for deaf readers, it is fair to point out that the phonological and semantic preview effects are not specific to deaf readers. What remains to be discovered is the type of parafoveal information that uniquely contributes to deaf readers for their lexical access.

\section{Activation of sign-based representation}

Reading is known to be difficult for deaf readers (Kelly \& BaracCikoja, 2007; Mayberry et al. 2011). The use of phonological codes in word recognition for deaf readers is controversial. Although some studies have suggested the involvement of phonological codes (Daigle \& Armand, 2008; Kelly, 2003), other findings, not only from alphabetic scripts (Bélanger, Baum, \& Mayberry, 2012a; Cripps, McBride, \& Forster, 2005), but also from scripts like Chinese (Chincotta \& Chincotta, 1996), have not shown evidence for this notion. Bélanger et al. (2012a) suggested that findings of deaf readers using phonological codes could be due to the effect of orthography, given the tight spelling-sound mappings in alphabetic scripts.

Some evidence has shown that deaf readers may rely on sign-based representations during word recognition. Sign languages are visual-gestural languages, perceived visually and expressed via linguistically-governed hand, arm and body gestures, along with facial expressions. There are four formational parameters of signs, including hand shape, orientation, movement, and location (Battison, 1978; Stokoe, Casterline, \& Croneberg, 1965), and they are referred to as the sign phonology. Sign phonology can be analogous to phonology in spoken language. However, they are different in terms of - but not only in terms of - the fact that sign-phonological elements are not based on 
sounds. These four formational parameters are valid not only in American Sign Language (ASL), but also in Chinese (see, e.g., W. Chen, 2007).

Ormel, Hermans, Knoors, and Verhoeven $(2009,2012)$ studied the sign activation of Dutch deaf children in a concept-judging task. They presented deaf individuals with stimulus pairs (sign-picture or word-picture pairs) simultaneously and asked them to judge whether the two stimuli referred to the same concept. When the two stimuli were semantically unrelated, deaf children were slower in response to pairs that had an overlap in sign phonology in Sign Language of the Netherlands (NGT) than to pairs with dissimilar sign phonologies. They argued that the two stimuli in the pairs activate various signphonology formational parameters, and that these elements in turn activate neighboring signs, thus creating an interference effect and leading to response difficulty. Morford et al. (2011) found similar results in a semantic-relatedness judgment task. For words that were not semantically related (NO responses), deaf bilinguals of ASL and English needed a longer time and made more mistakes in judging words that shared sign phonology in ASL translations than for those that did not. However, for words that were semantically related (YES responses), those that shared sign phonology were responded to faster than those without similarities in sign phonology. These findings suggest that when processing words, deaf readers activate sign translations of words, but how these sign translations affect word recognition may depend on the required response. The activation of sign translations during word recognition is not restricted to deaf sign language users. Grote and Linz (2003) used tasks similar to those of Ormel et al. $(2009,2012)$ and found that hearing individuals who knew sign languages also activated sign translations during word recognition. To summarize, the findings from these studies indicate that sign language users activate sign representations during word recognition.

This activation of sign phonology is also found during sentence reading. Treiman and Hirsh-Pasek (1983) presented deaf readers with sentences containing at least three words with similar sign phonologies and found that deaf readers made significantly more errors when judging the acceptability of these sentences, as compared to control sentences that contained words that were unrelated in sign phonology. Recently, Bélanger, Morford, and Rayner (2013b) manipulated the relatedness in ASL phonology of two words in a sentence and studied the influence of reading ability on sign activation during sentence reading in an eyetracking study. When the target word was preceded by a semantically unrelated word that shared sign features in ASL, fixation durations on the target word among less skilled deaf readers were longer than with an ASL-phonologically unrelated preceding word.

\section{The present study}

Previous studies have shown that sign phonology can lead to both facilitation and interference effects, and this discrepancy calls for additional tests. Furthermore, even though there is clear evidence for sign activation during foveal processing among signers (Grote \& Linz 2003; Morford et al., 2011; Treiman \& Hirsh-Pasek, 1983), it is not known yet whether sign phonology is activated during early parafoveal processing. In the present study, we set out to investigate these issues by testing Chinese deaf readers who use Chinese Sign Language (CSL).

We predicted that a preview cost effect would emerge due to sign-phonological relatedness, for two reasons. First, given that sign-phonologically related but not semantically related primes lead to an interference effect in foveal processing (Bélanger, Morford, \& Rayner, 2013b; Morford et al., 2011), analogously, it is likely that overlapping sign-phonological features afforded by parafoveal previews would interfere with the lexical access of target words when they were subsequently fixated. Second, given the evidence for a larger perceptual span, and thus for high efficiency in parafoveal processing, among deaf readers (Bélanger, Slattery, et al., 2012b), it would be likely for the incongruent information from the signphonologically related preview to take effect and introduce a preview cost.

\section{Method}

\section{Participants}

Forty-three moderately severe to profoundly deaf readers $(23$ female, 20 male; hearing loss ranging from 68 to $120 \mathrm{~dB}$ in the better ear, $M=99 \mathrm{~dB}, S D=12 \mathrm{~dB}$ ) from a deaf school in Beijing participated in the eyetracking study. They were 19.1 years old $(S D=1.94)$ and had used CSL as their main language for communication for 11.1 years $(S D=3.82)$. They had average nonverbal IQs according to the local norms (Zhang \& Wang, 1985) of Standard Progressive Matrices (Raven, Court, \& Raven, 1996). Thirty-nine fifth-graders (23 girls, 16 boys) with a mean age of 10.72 years $(S D=$ .29) participated as reading-level control readers. According to a silent-reading fluency test, the deaf readers and the control group read $329(S D=156)$ and $345(S D=85)$ characters $/ \mathrm{min}$, respectively, and the difference between the two groups was not significant $[F(1,80)=0.349, p=.556]$. This test was designed on the basis of the Reading Fluency subtest in Woodcock-Johnson III Tests of Achievement (Mather \& 
Woodcock, 2001). It requires readers to read and comprehend simple sentences and to judge the correctness of the contents as rapidly as possible. It has been used in previous studies to access children's reading ability in both alphabetic languages (Mayringer \& Wimmer, 2003; Moll, Fussenegger, Willburger, \& Landerl, 2009) and Chinese reading (Lei et al., 2011; Pan et al., 2011). Two independent groups of 21 and 17 undergraduate students participated in two norming tests for semantic relatedness and predictability. All of the participants had normal or corrected-to-normal vision and were native readers of Chinese.

\section{Materials}

Twenty-three ${ }^{1}$ CSL-phonologically related two-character word pairs were chosen. For each pair, two different sentence frames were developed, respectively using each of the two words as the target word, so that there were 46 experimental sentences in total. The target words were paired with three types of preview words: identical and CSL-phonologically related and unrelated previews. $^{2}$ Sign-phonological relatedness was defined as sharing at least two formational parameters (Morford et al., 2011; Ormel et al., 2012; see the Appendix for detailed information). In addition, the nonidentical preview and target words were not semantically related, did not share any constituent characters, and had no visual similarity or homophony between their constituent characters, thus avoiding any possible overlap at semantic, orthographic, or phonological (in terms of oral language) levels. The word frequencies and numbers of strokes of the three types of preview words were closely matched $(F$ values $<1)$. The semantic relatedness between the target words and the nonidentical preview words on a 5-point scale nicely reflected the intended design $[F(1,45)=2.601, p>.1]$. Table $1 \mathrm{~A}$ shows an example set of words in the different preview conditions.

The experimental sentences were 14 to 19 characters in length $(M=16, S D=1.4)$. The pretarget words (word $N$ ) were also always two-character words. The target words never appeared in the first seven or the last four characters of the sentence. Each sentence was presented only once to a participant, and the conditions were counterbalanced across participants. A teacher from the deaf school and a teacher from a primary

\footnotetext{
${ }^{1}$ Six pairs of target word pairs were removed, due to their semantic relatedness according to the rating results.

${ }^{2}$ Given that it was impossible to have enough of both (1) CSLphonologically and semantically related previews and (2) CSLphonologically related but semantically unrelated previews in a withinitem design, we chose to use the latter type of preview words in the present study, to test a pure sign-phonology effect.
}

Table 1 (A) Example set of words in the three preview conditions. (B) Means (and standard errors) of fixation measures for the different preview conditions

\begin{tabular}{|c|c|c|c|c|c|}
\hline & & & Identical & $\begin{array}{l}\text { CSL-Phonologically } \\
\text { Related }\end{array}$ & Unrelated \\
\hline \multirow[t]{6}{*}{ (A) } & \multicolumn{2}{|l|}{ Word } & 钢琴 & 电脑 & 态度 \\
\hline & \multicolumn{2}{|l|}{ Translation } & piano & computer & attitude \\
\hline & \multicolumn{2}{|c|}{ Pronunciation } & $\begin{array}{l}\text { gang1- } \\
\text { qin2 }\end{array}$ & dian4-nao3 & tai4-du4 \\
\hline & \multicolumn{2}{|l|}{ Frequency } & $\begin{array}{l}1.34 \\
(0.98)\end{array}$ & $\begin{array}{l}1.34 \\
(0.98)\end{array}$ & $\begin{array}{l}1.41 \\
(0.99)\end{array}$ \\
\hline & \multicolumn{2}{|c|}{ No. of strokes } & $\begin{array}{l}17.67 \\
(5.31)\end{array}$ & $\begin{array}{l}17.67 \\
(5.31)\end{array}$ & $\begin{array}{l}16.78 \\
\quad(5.02)\end{array}$ \\
\hline & \multicolumn{2}{|c|}{ Semantic Rating } & & $\begin{array}{l}2.00 \\
(0.52)\end{array}$ & $\begin{array}{l}1.84 \\
(0.49)\end{array}$ \\
\hline \multirow[t]{8}{*}{ (B) } & \multirow{2}{*}{$\begin{array}{l}\text { Skipping } \\
(\%)\end{array}$} & Deaf & $3.2(0.7)$ & $3.4(0.7)$ & $3.2(0.7)$ \\
\hline & & Hearing & $1.8(0.5)$ & $1.4(0.5)$ & $1.9(0.6)$ \\
\hline & \multirow[t]{2}{*}{ FFD (ms) } & Deaf & $328(8)$ & $418(8)$ & $391(8)$ \\
\hline & & Hearing & $290(7)$ & $380(7)$ & $390(7)$ \\
\hline & \multirow[t]{2}{*}{ GD (ms) } & Deaf & $468(11)$ & $570(12)$ & $541(12)$ \\
\hline & & Hearing & $417(11)$ & $565(10)$ & $581(10)$ \\
\hline & \multirow[t]{2}{*}{ TRT (ms) } & Deaf & 478 (12) & $601(13)$ & $578(12)$ \\
\hline & & Hearing & $433(11)$ & $595(11)$ & $605(11)$ \\
\hline
\end{tabular}

Frequency information (log-transformed numbers of occurrences per million) was obtained from Cai and Brysbaert (2010). FFD, firstfixation duration; GD, gaze duration; TRT, total reading time

school read the sentences and considered them to be suitable for the participants. The sentence contexts were written to be neutral. As a check, we presented sentence frames prior to the target words and asked the

CSL-phonologically related preview:

这次考试主要检验学生电脑演奏的技巧。

Unrelated preview:

这次考试主要检验学生态度演奏的技巧。

Identical preview / Target sentence:

这次考试主要检验学生钢琴演奏的技巧。

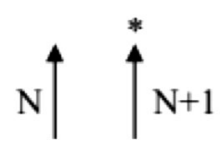

Fig. 1 A set of sample sentences. The preview words occupy the position of the target word $N+1$ and are replaced by the target word as soon as the reader's eyes (indexed by the asterisks in the figure) cross the invisible vertical boundary located between words $N$ and $N+1$. The target sentence translates as This test is mainly to examine students' piano playing skills. 
predictability norming participants to complete the sentences. The identical previews, CSL-phonologically related previews, and unrelated previews were correctly guessed eight times $(1.0 \%)$, three times $(0.4 \%)$, and no times $(0 \%)$, respectively. Figure 1 shows an example set of sentences.

\section{Apparatus}

Eye movements were recorded with an EyeLink 1000 system (running at $1000 \mathrm{~Hz}$ ). Sentences were presented in single lines vertically at a position one third of the way from the top of the screen of a 21-in. ViewSonic G220f monitor (resolution, 1,024 × 768 pixels; frame rate, $120 \mathrm{~Hz}$ ). The display change was completed within $12 \mathrm{~ms}$ after the eyes crossed the invisible boundary. Participants were seated $65 \mathrm{~cm}$ from the monitor with a chin-and-forehead rest. The font Song 40 was used, with one character spanning $1.4^{\circ}$ of visual angle. All recordings and calibrations were done monocularly for the right eye, and viewing was binocular.

\section{Procedure}

Participants were calibrated with a 5-point grid. They were instructed to read the sentences for comprehension. As is shown in Fig. 1, before readers' eyes crossed the invisible boundary located between words $N$ and $N+1$, they saw one of the three previews at the position of word $N+1$. The preview word was replaced by the target word immediately after the eyes crossed the boundary. Before a trial started, a fixation point appeared on the left side of the monitor for drift check. Fixation on the fixation point initiated presentation of the trial. An extra calibration was performed if tracking drifted from the fixation point presented prior to the experimental sentence. A total of 20 randomly selected sentences were followed by an easy yes-no comprehension question.

\section{Data analysis}

The data from two deaf readers who had less than $65 \%$ accuracy in answering the comprehension questions were excluded from the analyses. The hearing group $(M=86 \%, S D=5 \%)$ had a comprehension rate that was better than that of the deaf readers $(M=75 \%, S D$ $=6 \%), F(1,78)=79.8, p<.001$, but both groups had relatively high rates of correct answers. Using an algorithm for binocular saccade detection (Engbert \& Kliegl, 2003), standard eye movement measures of reading such as first-fixation durations (FFDs: the first fixation on a word in first-pass reading), gaze durations (GDs: the sum of all first-pass fixations on a word), and total reading times (TRTs: the sum of all fixations on a word, including regressive fixations) were determined. We removed the data for 20 trials (i.e., $0.5 \%$ ), due to participants' blinking, coughing, or bodies shaking during reading. FFDs shorter than $80 \mathrm{~ms}$ or longer than $800 \mathrm{~ms}$, GDs longer than 1,200 ms, and TRTs longer than $1,600 \mathrm{~ms}$ were removed from all analyses $(8 \%$ and $3 \%$ of the data for deaf and hearing readers, respectively). In addition, for all analyses, trials with regressions from the pretarget words $(2 \%$ and $1 \%$ of the data for deaf and hearing readers, respectively) were excluded, since these trials might reflect incomplete parafoveal processing of the preview words during fixations on pretarget words. Finally, $28 \%$ and $21 \%$ of the trials were removed from the duration analyses for the deaf and the hearing readers, respectively, due to late display changes (i.e., trials in which the saccade crossed the boundary during the final $15 \%$ of the saccade duration), because readers would be more likely to perceive a display change or flash at this time.

A total of 2,543 observations contributed to the duration analyses. Statistical inferences were based on planned comparisons of identical and CSLphonologically related previews, with the unrelated preview as a reference condition, and of the two reader groups. We allowed for varying intercepts for participants and words by using linear mixed models (LMMs) with the lmer program of the lme4 package (Bates, Maechler, Bolker, \& Walker, 2014) in the R environment (R Core Team, 2014). In LMMs, estimates 1.96 times larger than their standard errors are interpreted as being significant at the $5 \%$ level; this is because, given the number of participants and the large number of observations for each participant, the $t$ statistic in LMMs (i.e., M/SE) effectively corresponds to the $z$ statistic. We report log-transformed fixation durations as the dependent variable in the models because analyses of the residuals and inspection of the duration distributions strongly suggested that $\log$ transformation was required to meet the LMM assumptions (Kliegl, Masson, \& Richter, 2010). Analyses for untransformed and log-transformed durations yielded the same pattern of significance.

\section{Results}

Table 1B shows the raw participant means (and standard errors) for skipping rates, FFDs, GDs, and TRTs for each reader group. The main effects of preview and reader group and their interactions for skipping rates were not significant $[\mathrm{abs}(t$ values $)<1.0]$, indicating that 
the two groups did not differ in skipping rates in the three conditions.

The two reader groups did not differ in their FFDs $(b=$ $-.028, S E=.048, t=-0.57)$, GDs $(b=.075, S E=.057, t=$ $1.30)$, or TRTs $(b=.054, S E=.059, t=0.92)$ in the unrelated condition.

The identical PB (marginally) significantly interacted with reader group in the FFDs $(b=-.080, S E=.048, t=-2.29)$, and interacted significantly in the GDs $(b=-.179, S E=.040, t=-$ 4.47) and TRTs $(b=-.141, S E=.038, t=-3.68)$, indicating that the identical PBs, in both the early and late duration measures, were smaller for the deaf readers (FFD: $b=-.175, S E=$ $.025, t=-7.06$; GD: $b=-.178, S E=.029, t=-6.22$; TRT: $b=$ $-.229, S E=.027, t=-8.37$ ) than for the hearing readers (FFD: $b=-.254, S E=.024, t=-10.51 ; \mathrm{GD}: b=-.353, S E=.028, t=$ -12.62 ; TRT: $b=-.367, S E=.027, t=-13.71)$.

We observed significant interactions between the CSLphonologically related preview cost and reader group in the FFDs $(b=-.050, S E=-.025, t=-1.98)$ and GDs $(b=-.091$, $S E=.040, t=-2.26)$, with a marginally significant trend in the TRTs $(b=-.065, S E=.039, t=-1.69)$. Among the deaf readers, the CSL-phonological preview cost was significant in FFDs $(b=.060, S E=.028, t=2.15)$, and was marginally significant in GDs $(b=.050, S E=.029, t=1.73)$. A similar numerical trend was shown in the TRTs $(b=.039, S E=.028, t$ $=1.40$ ). No significant difference was apparent between the CSL-phonologically related and unrelated conditions among the control readers $[\operatorname{abs}(t$ values $)<1.5]$.

\section{Discussion}

In the present study, CSL-phonologically (but not semantically) related parafoveal previews were presented to deaf readers and to reading-level-matched hearing readers in order to test the parafoveal processing of sign phonology during the reading of Chinese sentences. We found early activation of sign phonology from parafoveal words only for the deaf readers. More critically, instead of the facilitation effect due to a parafoveally presented related preview that is normally shown in reading experiments, we observed in the present study a significant preview cost effect in our early fixation measure (i.e., FFD) for CSL-phonologically related preview words. This interference effect agrees with other results reported in foveal semantic relatedness judgment tasks and sentence-reading tasks, in which signs were not necessary to perform the tasks (Bélanger, Morford, \& Rayner, 2013b; Morford et al., 2011; Ormel et al., 2012). The preview cost that we observed in the present study extends earlier findings from foveal to early parafoveal processing and provides evidence for the notion that deaf readers are able to use a unique encoding strategy during reading (for a review, see Musselman, 2000), indicating a contribution of sign phonology to lexical access among sign language users.

The results of the present study also contribute to the understanding of the preview cost effect that has been reported recently. Using the standard foveal-priming paradigm, Zhou, Marslen-Wilson, Taft, and Shu (1999) reported that a semantic prime can cause both positive and negative priming effects: When the prime is presented briefly, the common properties are activated, and there is little competition between the semantic activation of the prime and target, leading to facilitation in lexical decision. Alternatively, if lexical access to the prime is more complete (typically due to a long stimulus onset asynchrony), nonoverlapping semantic representations and diverging aspects start to develop and result in competition between the prime and target, leading to inhibitory effects. Previous studies have shown that orthographic overlap also produces negative priming effects in word naming (H.-C. Chen \& Shu, 2001; Perfetti \& Tan, 1998) and typing (J.-Y. Chen \& Li, 2011) tasks. Taking these findings together, whether a prime leads to facilitation or inhibition may well depend on the depth of its lexical access.

The negative priming effect is analogous to the preview cost in the gaze-contingent boundary paradigm. A deeper level of lexical access is likely to be achieved when the parafoveal processing time is long and when parafoveal processing efficiency is high. Pan et al. (2015) obtained significant semantic PBs in silent reading but semantic preview costs in oral reading, and they concluded that reading aloud slows down the eyes and that readers thus have more opportunities to process the preview words; as a consequence, diverging features of the preview and the target start to develop and lead to a preview cost effect. Yan et al. (2015a) reported that an early semantic PB was canceled by subsequent processing costs, leading to a numerical preview cost. They argued that both fast access to semantics in Chinese and the high parafoveal processing efficiency of deaf readers contribute to this cost among Chinese deaf readers. As a consequence, accumulated diverging semantic representations from the previews eventually disrupted the processing of the target words at a late processing stage.

So far, there has been no evidence of a preview cost due to other types of information than semantics. One important theoretical contribution of the present study is its extension of the preview cost to parafoveal sign-relatedness. Notably, this preview cost in FFDs and the similar trends in later measures indicate early, strong, and long-lasting interference. Two factors might have contributed to the preview cost effect. First, deaf readers are known to allocate more attention to parafoveal 
information (Bavelier et al., 2006; Dye \& Bavelier, 2010), and thus have a larger perceptual span in reading (Bélanger, Slattery, et al., 2012b). Second, slow foveal reading may provide more opportunities for parafoveal processing (Yan, Luo, \& Inhoff, 2014). Both factors imply that deaf readers may achieve more complete access to the parafoveal preview words, which may lead to a competition between the preview and the target. As a consequence, extra efforts are needed to suppress the interference from the preactivated diverging information afforded by the CSL-phonologically related preview.

Previously, Bélanger, Morford, and Rayner (2013b) found a sign-phonological interference effect among deaf readers whose reading level was equivalent to 6th grade. In the present study, our sample consisted mainly of deaf readers with an average 5th-grade reading ability, which is largely consistent with the findings of Bélanger, Morford, and Rayner. Sign-phonological interference among more skilled readers (i.e., grade 8.9 or higher) has also been reported (Morford et al., 2011). Preview costs occur due to deep access to parafoveal information. This implies that with equal amounts of preview duration, the preview cost is more likely to be observed for individuals with high reading skill. For readers with low reading skill, parafoveal processing may be too slow to induce a preview cost. The result of a reliable preview cost effect among deaf readers with reading abilities equivalent to 5 th grade implies that these readers are efficient enough in their parafoveal processing of sign phonology to generate interference. When adding reading proficiency and preview duration as covariates in the present study, we found no significant interactions with these covariates [all $\operatorname{abs}(t$ values $)<1.3$ ], possibly due to inadequate statistical power of the data or to relatively small variance in the covariates. After all, the present study was not in a good position to test the influence of reading ability on the parafoveal sign-phonological processing of words. To this end, it will be of great interest for future research to test the parafoveal sign-phonology effect with deaf readers of different reading proficiencies.

In sum, the present study has demonstrated that Chinese deaf readers activated the sign-phonology information of parafoveal words during reading. Together with previous findings (Bélanger, Mayberry, \& Rayner, 2013a; Morford et al., 2011; Yan et al., 2015), our results suggest that deaf readers are flexible in the ways that they choose to code words.

Author note This research was funded by DFG project grants (Nos. LA2884/2-1 and KL955/18). The data and R scripts used in this article are available at the Potsdam Mind Research Repository (http://read. psych.uni-potsdam.de/PMR2/).
Appendix

Table 2 Similarities between CSL-phonologically related words

\begin{tabular}{|c|c|c|c|c|}
\hline & Hand Shape & Orientation & Movement & Location \\
\hline 干净-清楚 & 1 & 2 & 2 & 2 \\
\hline 简单-便宜 & 2 & 2 & 2 & 2 \\
\hline 命令-处罚 & 2 & 2 & 2 & 2 \\
\hline 经验-研究 & 2 & 2 & 2 & 2 \\
\hline 自己一孤独 & 2 & 2 & 2 & 2 \\
\hline 颜色-杂乱 & 2 & 2 & 2 & 2 \\
\hline 天津-经常 & 2 & 2 & 2 & 2 \\
\hline 桥梁-见面 & 2 & 2 & 0 & 2 \\
\hline 自私一足够 & 1 & 2 & 2 & 2 \\
\hline 杂乱一尝试 & 2 & 2 & 2 & 2 \\
\hline 叶子-月亮 & 2 & 0 & 2 & 2 \\
\hline 教育一纸张 & 2 & 2 & 2 & 2 \\
\hline 微笑-愿意 & 2 & 2 & 0 & 2 \\
\hline 困难-知道 & 2 & 2 & 0 & 2 \\
\hline 态度-怎样 & 2 & 2 & 1 & 2 \\
\hline 电脑-钢琴 & 2 & 2 & 1 & 2 \\
\hline 边缘-设计 & 1 & 2 & 2 & 2 \\
\hline 年老-消瘦 & 1 & 2 & 2 & 2 \\
\hline 糊涂-影响 & 2 & 2 & 2 & 2 \\
\hline 黑色-后悔 & 1 & 2 & 1 & 2 \\
\hline 饱餐一怀孕 & 2 & 2 & 0 & 2 \\
\hline 蘑菇-雨伞 & 1 & 2 & 2 & 2 \\
\hline 婏嘴－羡慕 & 2 & 2 & 2 & 2 \\
\hline
\end{tabular}

0 refers to different, 1 refers to similar, and 2 refers to identical

\section{References}

Battison, R. (1978). Lexical borrowing in American sign language. Silver Spring: Linstok Press.

Bates, D., Maechler, M., Bolker, B., \& Walker, S. (2014). lme4: Linear mixed-effects models using Eigen and S4 (R package version 1.1-8). Retrieved from http://CRAN.R-project.org/package=lme4

Bavelier, D., Dye, M. W. G., \& Hauser, P. C. (2006). Do deaf individuals see better? Trends in Cognitive Sciences, 10, 512-518. doi:10.1016/ j.tics.2006.09.006

Bélanger, N. N., Baum, S. R., \& Mayberry, R. I. (2012a). Reading difficulties in adult deaf readers of French: Phonological codes, not guilty! Scientific Studies of Reading, 16, 263-285.

Bélanger, N. N., Mayberry, R. I., \& Rayner, K. (2013a). Orthographic and phonological preview benefits: Parafoveal processing in skilled and less-skilled deaf readers. Quarterly Journal of Experimental Psychology, 66, 2237-2252.

Bélanger, N. N., Morford, J. P., \& Rayner, K. (2013b). Automatic American Sign Language (ASL) activation during reading in ASLEnglish deaf bilinguals. Paper presented at the 17th European Conference on Eye Movements, Lund, Sweden.

Bélanger, N. N., Slattery, T. J., Mayberry, R. I., \& Rayner, K. (2012b). Skilled deaf readers have an enhanced perceptual span in reading. Psychological Science, 23, 816-823. 
Cai, Q., \& Brysbaert, M. (2010). SUBTLEX-CH: Chinese word and character frequencies based on film subtitles. PLOS ONE, 5(e10729), 1-8. doi:10.1371/journal.pone.0010729

Chen, H.-C., \& Shu, H. (2001). Lexical activation during the recognition of Chinese characters: Evidence against early phonological activation. Psychonomic Bulletin \& Review, 8, 511-518. doi:10.3758/ BF03196186

Chen, J.-Y., \& Li, C.-Y. (2011). Word form encoding in Chinese word naming and word typing. Cognition, 121, 140-146.

Chen, W. (2007). On some essentials of sign language. Journal of Nanjing Technical College of Special Education, 1, 27-29. Original work in Chinese.

Chincotta, M., \& Chincotta, D. (1996). Digit span, articulatory suppression, and the deaf: A study of the Hong Kong Chinese. American Annals of the Deaf, 141, 252-257.

Cripps, J. H., McBride, K. A., \& Forster, K. I. (2005). Lexical processing with deaf and hearing: Phonology and orthographic masked priming. Arizona working papers in second language acquisition and teaching (Vol. 12, pp. 31-44). Tucson, AZ: University of Arizona.

Daigle, D., \& Armand, F. (2008). Phonological sensitivity in severely and profoundly deaf readers of French. Reading and Writing, 21, 699 717.

Dye, M. W. G., \& Bavelier, D. (2010). Attentional enhancements and deficits in deaf populations: An integrative review. Restorative Neurology and Neuroscience, 28, 181-192. doi:10.3233/RNN2010-0501

Engbert, R., \& Kliegl, R. (2003). Microsaccades uncover the orientation of covert attention. Vision Research, 43, 1035-1045. doi:10.1016/ S0042-6989(03)00084-1

Goswami, U., \& Bryant, P. (1990). Phonological skills and learning to read. Hove: Erlbaum.

Grote, K., \& Linz, E. (2003). The influence of sign language iconicity on semantic conceptualization. In W. G. Muller \& O. Fisher (Eds.), From sign to signing: Iconicity in language and literature 3 (pp. 23-40). Amsterdam: Benjamins.

Hoosain, R. (1992). Psychological reality of the word in Chinese. Advances in Psychology, 90, 111-130.

Inhoff, A. W., \& Liu, W. (1998). The perceptual span and oculomotor activity during the reading of Chinese sentences. Journal of Experimental Psychology: Human Perception and Performance, 24, 20-34. doi:10.1037/0096-1523.24.1.20

Kelly, L. (2003). The importance of processing automaticity and temporary storage capacity to the differences in comprehension between skilled and less skilled college-age deaf readers. Journal of Deaf Studies and Deaf Education, 8, 230-249.

Kelly, L., \& Barac-Cikoja, D. (2007). The comprehension of skilled deaf readers: The roles of word recognition and other potentially critical aspects of competence. In K. Cain \& J. Oakhill (Eds.), Children's comprehension problems in oral and written language: A cognitive perspective (pp. 244-279). New York: Guilford.

Kliegl, R., Hohenstein, S., Yan, M., \& McDonald, S. A. (2013). How preview space/time translates into preview cost/benefit for fixation durations during reading. Quarterly Journal of Experimental Psychology, 66, 581-600. doi:10.1080/17470218.2012.658073

Kliegl, R., Masson, M. E. J., \& Richter, E. M. (2010). A linear mixed model analysis of masked repetition priming. Visual Cognition, 18, 655-681.

Laubrock, J., \& Hohenstein, S. (2012). Orthographic consistency and parafoveal preview benefit: A resource-sharing account of language differences in processing of phonological and semantic codes. Behavioral and Brain Sciences, 35, 292-293. doi:10.1017/ S0140525X12000209

Lei, L., Pan, J., Liu, H., McBride-Chang, C., Li, H., Zhang, Y., . . Shu, H. (2011). Developmental trajectories of reading development and impairment from ages 3 to 8 years in Chinese children. Journal of Child Psychology and Psychiatry, 52, 212-220.
Mather, N., \& Woodcock, R. W. (2001). Woodcock-Johnson III tests of cognitive abilities: Examiner's manual. Itasca: Riverside.

Mayberry, R. I., del Giudice, A., \& Lieberman, A. (2011). Reading achievement in relation to phonological coding and awareness in deaf readers: A meta-analysis. Journal of Deaf Studies and Deaf Education, 16(2), 164-188.

Mayringer, H., \& Wimmer, H. (2003). Salzburger Lesescreening (SLS 14). Berne: Hans Huber.

McConkie, G. W., \& Rayner, K. (1975). The span of the effective stimulus during a fixation in reading. Perception \& Psychophysics, 17, 578-586. doi:10.3758/BF03203972

Moll, K., Fussenegger, B., Willburger, E., \& Landerl, K. (2009). RAN is not a measure of orthographic processing. Evidence from the asymmetric German orthography. Scientific Studies of Reading, 13(1), 125.

Morford, J. P., Wilkinson, E., Villwock, A., Piñar, P., \& Kroll, J. F. (2011). When deaf signers read English: Do written words activate their sign translations? Cognition, 118, 286-292.

Musselman, C. (2000). How do children who can't hear learn to read an alphabetic script? A review of the literature on reading and deafness. Journal of Deaf Studies and Deaf Education, 5, 9-31.

Ormel, E., Hermans, D., Knoors, H., \& Verhoeven, L. (2009). The role of sign phonology and iconicity during sign processing: The case of deaf children. Journal of Deaf Studies and Deaf Education, 14, 436448. doi:10.1093/deafed/enp021

Ormel, E., Hermans, D., Knoors, H., \& Verhoeven, L. (2012). Cross-language effects in written word recognition: The case of bilingual deaf children. Bilingualism: Language and Cognition, 15, 288-303

Pan, J., Laubrock, J., \& Yan, M. (2015). Preview duration modulates semantic preview benefit/cost in reading. Under Review.

Pan, J., McBride-Chang, C., Shu, H., Liu, H., Zhang, Y., \& Li, H. (2011). What is in the naming? A 5-year longitudinal study of early rapid naming and phonological sensitivity in relation to subsequent reading skills in both native Chinese and English as a second language. Journal of Educational Psychology, 103, 897-908.

Perfetti, C. A., \& Tan, L. H. (1998). The time course of graphic, phonological, and semantic activation in Chinese character identification. Journal of Experimental Psychology: Learning, Memory, and Cognition, 24, 101-118. doi:10.1037/0278-7393.24.1.101

Raven, J. C., Court, J. H., \& Raven, J. (1996). Standard Progressive Matrices. Oxford: Oxford Psychologists Press.

Rayner, K. (1975). The perceptual span and peripheral cues in reading. Cognitive Psychology, 7, 65-81.

Rayner, K. (2009). Eye movements and attention in reading, scene perception, and visual search. The Quarterly Journal of Experimental Psychology, 62, 1457-1506. doi:10.1080/17470210902816461

R Core Team. (2014). R: A language and environment for statistical computing [Software package]. R Foundation for Statistical Computing, Vienna, Austria. Retrieved from www.R-project.org

Schotter, E. R. (2013). Synonyms provide semantic preview benefit in English. Journal of Memory and Language, 69, 619-633.

Schotter, E. R., Angele, B., \& Rayner, K. (2012). Parafoveal processing in reading. Attention, Perception, \& Psychophysics, 74, 5-35. doi: 10.3758/s13414-011-0219-2

Stokoe, W., Casterline, D., \& Croneberg, C. (1965). A dictionary of American sign language on linguistic principles. Washington, DC: Gallaudet College Press.

Treiman, R., \& Hirsh-Pasek, K. (1983). Silent reading: Insights from second-generation deaf readers. Cognitive Psychology, $15,39-65$.

Yan, M., Luo, Y., \& Inhoff, A. W. (2014). Syllable articulation influences foveal and parafoveal processing of words during the silent reading of Chinese sentences. Journal of Memory and Language, 75, 93103. doi:10.1016/j.jml.2014.05.007 
Yan, M., Pan, J., Bélanger, N. N., \& Shu, H. (2015a). Chinese deaf readers have enhanced sensitivity towards parafoveal semantic information. Journal of Experimental Psychology: Learning, Memory, and Cognition, 41, 254-261. doi:10.1037/xlm0000035

Yan, M., Richter, E. M., Shu, H., \& Kliegl, R. (2009). Chinese readers extract semantic information from parafoveal words during reading. Psychonomic Bulletin \& Review, 16, 561-566. doi:10.3758/PBR. 16.3.561

Yan, M., Risse, S., Zhou, X., \& Kliegl, R. (2012a). Preboundary duration modulates semantic preview benefit for word $N+1$ and $N+2$ in Chinese reading. Reading and Writing, 25, 1093-1111.

Yan, M., Zhou, W., Shu, H., \& Kliegl, R. (2012b). Lexical and sub-lexical semantic preview benefits in Chinese reading. Journal of Experimental Psychology: Learning, Memory, and Cognition, 38, 1069-1075. doi:10.1037/a0026935
Yan, M., Zhou, W., Shu, H., \& Kliegl, R. (2015b). Perceptual span depends on font size during the reading of Chinese sentences. Journal of Experimental Psychology: Learning, Memory, and Cognition, 41, 209-219. doi:10.1037/a0038097

Yang, J., Wang, S., Tong, X., \& Rayner, K. (2012). Semantic and plausibility effects on preview benefit during eye fixations in Chinese reading. Reading and Writing, 25, 1031-1052. doi:10.1007/ s11145-010-9281-8

Zhang, H., \& Wang, X. (1985). 瑞文标准推理测验手册 [Raven's IQ Reasoning Standardized Test]. Beijing: Department of Psychology, Beijing Normal University Press.

Zhou, X., Marslen-Wilson, W., Taft, M., \& Shu, H. (1999). Morphology, orthography, and phonology in reading compound Chinese. Language \& Cognitive Processes, 14, 525-565. doi:10.1080/ 016909699386185 